\title{
Research on Optimization Strategies of Campus Plant Landscape in Shenyang
}

\author{
Haiyan $\mathrm{Qu}^{1,}$,, $\mathrm{Bo}$ Zhao ${ }^{2, \mathrm{~b}}$
}

\author{
1Shenyang Jianzu University,No.9,Hunnan Road(east),Shenyang,Liaoning Province, China \\ ²Shenyang Jianzu University,No.9,Hunnan Road(east),Shenyang,Liaoning Province, China \\ aguqujun@126.com, b423631271@qq.com
}

Keywords:universitie's campus; plant landscape; environment monitor; optimization strategies

\begin{abstract}
With the rapid advance of urbanization process, particle matters from the atmosphere has gradually become the primary pollutant of the air in cities. This paper selected the university campus of Shenyang - the north city of which the pollution is serious as the research target. Through investigation and environmental monitor to green space of campus of universities of Shenyang, compared the air environmental quality inside/outside the campus, analyzed the selection of plant varieties, structural characters of plant communities and the relation between plants and air/environment quality. Summarized issues existed in vegetative landscape of universities such as the plant varieties of new campus being single, the structure of plant communities being single, late maintenance being not available, the optimization on air quality being short, etc, and influences made by these issues on universities' campus of Shenyang in terms of landscape, ecology and safety, proposed optimization strategies of the plant landscape of universities of Shenyang, further improved the environment quality and landscape quality of campus of universities.
\end{abstract}

\section{General Situation of Research Areas and Research Methods}

1.1 General Situation of Research Areas. Plant landscape of universities' campus is an important constituent part of campus construction, not only providing beautiful living environment to teachers and students in school, but also playing the role to improve campus's microclimate and purify the air, etc. Plant landscape of universities' campus should be different from that of streets featured with practicability and that of parks featured with ornament.

Shenyang, as the largest city of northeast with area about $3500 \mathrm{~km}^{2}$, has 48 universities in total which are distributed Heping District, Tiexi District, Dadong District, Huanggu District and Dongling District all belonging to old urban area; and Hunnan New District and Shenbei New District both belonging to new urban area. Due to different building time and economic development extent of each area, the characters of plant communities, air quality and climate of universities in each area are also different. The universities in old urban area were built early in general and those in south and north development zone were built relatively late. Plant landscape is a kind of sustainable and developmental landscape, and its growth cycle and growth duration influences the current effect very much. The old universities under investigation included Northeastern University, Chongshan School Zone of Liaoning University, Shenyang Agricultural University and Shenyang Jianzhu University. The comparative investigation between new school zones and old ones provided good conditions to research the influences of plant growth duration on environment of campuses' landscape.

1.2 Research Methods. Adopted site survey, field monitor, statistical analysis, aesthetic evaluation, species diversity evaluation and other research methods.

1.2.1 Site survey: Surveyed the functional target type, area, name of species, quantity of species in each community selected in each sampling land, recorded the quantity, height, DBH, crown width, level of hierarchy, condition of growth and heath, growth potential and growth environment of each specie. Evaluated plant adaptability, stress tolerance and growth potential according to plant growth state and lush extent of leaves when site survey.

1.2.2 Field monitor: Selected 11 different lands of phytocenosis from each university as spots for air quality monitor. Conducted monitor testing from July, 2015 for four months. Took the university 
gate as reference point, monitored once every 10 days, divided each time to three time sections----morning, noon and evening, all monitor spots conducted monitor simultaneously and recorded the concentration value of PM10/2.5, wind speed and weather condition at different monitor spots during different time sections and filled the data in Excel for easy statistics, analysis and use.

1.2.3 Evaluation of diversity:Surveyed by areas, selected 5 standard lands in each functional use area and the selection method of standard lands was diagonal method, each standard land lying at all four corners and the center with area $0.08 \mathrm{hm}^{2}$. The diversity of plant species (D), adopting Shannon-Wiener index ${ }^{[1]}$, mainly used to reflect the variety extent of plants, is a comprehensive reflect of plant species and uniformity:

$$
D=3.329\left(\lg N-1 / N \times \sum_{i=1}^{S} \lg n_{i}\right)
$$

Wherein, the implication of $\mathrm{S}$ and $\mathrm{N}$ is the same with above, ni means the individual number of the plant species ranking i.

1.2.4 Aesthetic evaluation:Ornamental value of plant species was mainly reflected in crowns, leaves, flowers, fruits and barks, hence, these five indexes was the scoring basis. Because the ornamental values of performances, leaves, flowers, fruits and barks were different, according to the proposals of most people and landscape architectural experts, they were given weight coefficient 2,3 , $3,1,1$ respectively. The sum of the scores of performances, leaves, flowers, fruits and barks multiplied with their respective weight coefficient was the ornamental index of a certain tree variety.

$1($ ornamental index $)=2($ performances $)+3$ (leaves $)+3($ flowers $)+1($ fruits $)+1(\text { barks })^{[2]}$

The scoring for crowns, leaves, flowers, fruits and barks were all divided to 3 levels: excellent, good, common with 3 score, 2 score and 1 score respectively. Then the ornamental values of different plant species were figured out ${ }^{[3]}$. All data were analyzed by adopting excel、 spss.

1.3 The Selection of Monitor Sampling Lands of Monitor Spots. According to the difference of the universities' locations and building duration, selected four representative universities for air quality monitor, including Shenyang Agriculture University, Shenyang Jianzhu University, Liaoning University, Northeastern University. Selected pure forest and mixed forest of different varieties of which the area is large and growth is flourishing in campuses for 3-month actual monitoring and data analysis.

\section{Results and Analysis}

Among universities under investigation, due to the different of building time, campus culture, economic level and geographic location, the configuration of plant communities and landscape features are apparently different. Through investigation, we acquainted that the school zones locating in central urban areas were mostly old zone which are scattered; the school zones locating in south and north development zone were mostly new zones distributed centrally of which the characters of their plant communities have relatively obvious differences.

2.1 Analysis of Plant Status. Northeastern University was in downtown, an old school zone, with long plant-age. The types of trees were mainly Pinus tabuliformis Carrière, Sabina chinensis, Prunus persica f. rubro-plena, Robinia pseudoacacia, acer monoes , Picea asperata, Michelia alba DC., Malus spectabilis , Salix babylonica Ailanthus altissima, Ginkgo biloba , Ulmus pumila, Koelrenteria paniculata, Morus alba cv.Tortuosa, Prunus armeniaca, Crataegus pinnatifida Bunge, Rhustyphina, Cotinus coggygria, Euonymus maackii Rupr.; types of shrubs were mainly Ligustrum obtusifolium Sieb. et Zucc., Forsythia, Hemerocallis, Syzygium aromaticum, Swida alba Opiz, Weigela florida (Bunge) A. DC, acer monoes, Berberis thunbergii var. atropurpurea Chenault, Berberis thunbergii DC.; flag types were mainly Trifolium repens, lawn, Trifolium repens $L$, Hylotelephium erythrostictum (Miq.) H. Ohba, Spiraea japonica Gold Mound, Hosta plantaginea 
(Lam.) Aschers; parterre flowers are mainly:Tagetes erecta L, Salvia splendens Ker-Gawler, Canna indica $L$., etc. The plant species in teaching quarter was single and that in dorm quarter was abundant.

Chongshan School Zone of Liaoning University was in Tiexi District, old school zone with long plant-age. Liaoning University building layout was scattered, most of evergreen plants were pine, cypress and yew, and most of deciduous trees were Sophora japonica Linn. and Ginkgo biloba L. with long plant-age. Many tree-shrubs mixed forest. The pure forests of trees at big scale include Acer mono Maxim, Ginkgo biloba L., Malus and Sophora japonica Linn, among which brilliant Malus and acer monoes were varieties newly planted in these years-though the ages were small but growth well.

Shenyang Agriculture University was in Dongling District which has the longest history and largest area; its plant-age was the longest, types of plants were the most abundant and plant communities were the most complex with plant 26 families, 37 genus and 61 types. Pure forest was few in its campus and most are tree-shrub-grass, tree-grass or shrub-grass forests. The main types of trees were Pinus tabuliformis Carrière, Salix matsudana f. pendula, Salix matsudana f. pendula, Robinia pseudoacacia, acer monoes, PiceaasperataMast and Ginkgo biloba L.,etc. Main shrubs types were: Ginkgo biloba L., Syzygium aromaticum, Hydrangea paniculata, Rosa xanthina Lindl., etc. The layout of green space was arranged mostly around buildings and only a few formed isolated landscape areas: the style of landscape was solemn, rigorous, generous, rough, decorous and staid. The plant landscape was dominated by Pinus tabuliformis Carrière and other pine families with apparent seasonal colors ${ }^{[4]}$.

Shenyang Jianzhu University was in Hunnan New District, built in 2002, was a new school zone. The plant-age in campus was short and most of plant communities were pure forests and a few were mixed forests. The dorm quarter was zonal area and the plant configuration there was dominated by Populusalba, saponin, Syzygium aromaticum and Ligustrum obtusifolium Sieb. et Zucc.. The Populusalba with double-color leaves formed exclusive scenery in summer, foiling the atmosphere of the whole living quarters. However, types of shrubs were relatively few, making the plant landscape of apparent horizon relatively thin. Pure forests of Rhustyphina in living service quarter were attractive landscape spots and both the orderly leaves in summer and red fruits in autumn were excellent plant landscape-making elements. However, the large exposed area of square, plant-age and insufficient quantity made good landscape of the square under forests not formed, not applicable for students to stay in hot summer. The tree varieties was relatively abundant- trees have Populus bolleana, Robinia pseudoacacia, Robinia pseudoacacia, Salix babylonica, acer monoes, etc, shrubs have acer monoes, Cerasus tomentosa, Syzygium aromaticum, Ligustrum obtusifolium Sieb. etc. But special courtyard style of teaching quarter made the plant configuration very single, even some courtyards only had a few small trees and lawns for landscape making, not satisfying the demand of study and living as a courtyard. Inside Shenyang Ligong University, the green space at sides of the main road grew a large number of pure forests of Populus bolleana, Saliz matsudana and Robinia pseudoacacia; The plant configuration in landscape areas taking the library as the center was relatively abundant, forming tree-shrub-grass mixed forests including Amygdalus triloba, PiceaasperataMast, Sabina chinensis, Ligustrum obtusifolium Sieb. et Zucc., Amygdalus triloba, etc. Trees in teaching quarter were dominated by large-area pure forests of Populus bolleana and Robinia pseudoacacia and shrubs were dominated by mixed forests of Ligustrum obtusifolium, Amygdalus triloba and Syzygium aromaticum.

2.2 Analysis of the Diversity of Species . The species in all four areas of Shenyang universities were abundant and the degree of diversity is high (Table1). In teaching area, the species of Shenyang Agriculture University was the most abundant with the diversity index 0.96, the second was Liaoning University with index 0.94 , the abundance index of Northeast University is low with 0.84 and that of Shenyang Jianzhu University is the lowest with 0.81. In living quarter, the abundance indexes of all universities were almost the same and species were abundant; In public activity quarters, the rank of species abundance indexes of the four universities was: Shenyang Agriculture University (0.96), Liaoning University (0.94), Northeastern University (0.86) Shenyang Jianzhu University (0.83). On 
the whole, seen from universities of Shenyang, the species of plants in living quarters was abundant, while abundance degree in environment of teaching and public areas was relatively small. So the species of these two areas should be increased appropriately to create a beautiful plant landscape. ${ }^{[5]}$

Table 1. The diversity indexes of the four universities

\begin{tabular}{|c|c|c|c|c|c|c|}
\hline \multirow[t]{2}{*}{ Quarters } & \multicolumn{5}{|c|}{ Diversity Indexes of Sepcies } & \multirow[b]{2}{*}{ Jianzhu } \\
\hline & Northeastern & Liaoning & Shenyang & Agriculture & Shenyang & \\
\hline & University & University & Universily & & Universily & \\
\hline leaching & 0.84 & 0.94 & 0.96 & & 0.81 & \\
\hline Living quarter & 0.94 & 0.94 & 0.93 & & 0.89 & \\
\hline $\begin{array}{l}\text { Public activity } \\
\text { quarter }\end{array}$ & 0.86 & 0.94 & 0.96 & & 0.83 & \\
\hline
\end{tabular}

The comprehensive condition of the plant landscape in living quarters of the four universities was approximate; the overall score of living quarters was lower than that of teaching quarters, the diversity of configuration mode of communities of Liaoning University and Shenyang Agriculture University was overlapping, making the plant landscape not match well in space; the gap of scores of public activity quarters was the most obvious, the variation of the seasonal aspects of plants in Northeast University was not obvious and the configuration mode of plant space was poor. The comprehensive scores of the three quarters of Shenyang Universities were approximate and the integrity of plant landscape was appropriate. The construction of public activity quarters should be paid much attention to strengthen to make the species of plants more abundant, the seasonal variation of plant landscape more obvious and the matching of plants well-proportioned.

2.3 Analysis of the Degree of Landscape Aesthetics. Among plants of Shenyang Universities, there were more flower-appreciation plants with good ornamental characters; the matching proportion of evergreen plants and deciduous plants was overlapping with low ling type diversity and the configuration mode of plant communities was single.

Table 2. Table of comprehensive scores of the ornamental value of plant species

\begin{tabular}{|c|c|c|c|c|c|c|}
\hline Species of plants & $\begin{array}{l}\text { cro } \\
\text { wn } \\
\times 2\end{array}$ & $\begin{array}{l}\text { leaves(shape } \\
\text { 、 color } \\
\text { whether } \\
\text { evergreen)× } \\
3\end{array}$ & $\begin{array}{l}\text { flower(c } \\
\text { olor } 、 \\
\text { shape 、 } \\
\text { fragranc } \\
\text { e) } \times 3\end{array}$ & $\begin{array}{l}\text { fruit(co } \\
\text { lor } \\
\text { shape) } \\
\times 1\end{array}$ & bark $\times 1$ & $\begin{array}{l}\text { Comprehensive } \\
\text { scores }\end{array}$ \\
\hline Pinus tabuliformis & 3 & 3 & 1 & 1 & 1 & 20 \\
\hline Platycladusorientalis(Linn.) & 2 & 2 & 1 & 1 & 1 & 15 \\
\hline Robinia pseudoacacia $L$ & 1 & 1 & 3 & 1 & 1 & 16 \\
\hline Acer truncatum Bunge & 1 & 3 & 2 & 2 & 2 & 21 \\
\hline Cotinus coggygria & 2 & 3 & 2 & 1 & 1 & 21 \\
\hline Siberian Apricot & 1 & 1 & 3 & 2 & 2 & 18 \\
\hline Q. liaotungensis & 1 & 2 & 1 & 2 & 1 & 14 \\
\hline Sabina chinensis & 3 & 2 & 1 & 1 & 1 & 17 \\
\hline Populus canadensis & 1 & 1 & 1 & 1 & 1 & 10 \\
\hline Salixbabylonica & 2 & 1 & 1 & 1 & 1 & 12 \\
\hline F.atropuTpurea & 2 & 3 & 2 & 1 & 2 & 22 \\
\hline
\end{tabular}




\begin{tabular}{|c|c|c|c|c|c|c|}
\hline Prunus triloba & 1 & 1 & 3 & 1 & 1 & 16 \\
\hline Prunus serrulata & 1 & 1 & 3 & 1 & 2 & 17 \\
\hline Cerasus tomentosa (Thunb.) & 1 & 1 & 3 & 3 & 1 & 18 \\
\hline Acerginnala & 1 & 3 & 2 & 2 & 2 & 21 \\
\hline Xanthoceras & 1 & 2 & 2 & 3 & 1 & 18 \\
\hline Lonicera & 1 & 1 & 2 & 3 & 1 & 15 \\
\hline $\begin{array}{l}\text { Ligustrum obtusifolium } \\
\text {...... }\end{array}$ & 1 & 1 & 1 & 1 & 1 & 10 \\
\hline
\end{tabular}

The statistics and analysis result of Table 2 showed: seen from the rank of ornamental indexes, the ornamental values of Cotinus coggygria, Acer truncatum Bunge, Acerginnala, ginkgo biloba were the highest which reached over 20 in general and they were the landscape of plant species of colorful leaves in autumn. The second was Pinus tabuliformis, Abies fabric, Sabina chinensis and other evergreen plant species. The third was Xanthoceras sorbifolia Bunge, Cerasus tomentosa (Thunb.) Wall., Amygdalus triloba, Siberian Apricot, etc, of which the fruits or flowers were pretty that could constitute the landscape for summer to appreciate flowers and for autumn to appreciate fruits. The species with the lowest ornamental values was: Ligustrum obtusifolium Sieb. et Zucc, Populus Canadensis, etc, and these species had no special aspects in crown shape, leaves, flowers, fruits and barks. It could be concluded from the result above: leaf-appreciation species (autumn landscape)> evergreen species (winter landscape) > flower-appreciation and fruit-appreciation species> common species. The landscape level based on the above was formed: very high, high, medium, common. When conducting plant selection and configuration, if we want to improve the landscape value of amenity forests, we should collocate some ornamental species properly to increase landscape quality.

2.4 Analysis of Dust-stagnation Volume

Table 3. Rank of dust-stagnation capacity of shrubs and vines

\begin{tabular}{|c|c|c|c|c|}
\hline \multirow[t]{2}{*}{ Species of plants } & \multicolumn{3}{|c|}{ Dust-stagnation volume $(\mathrm{g} \cdot \mathrm{m}-2)$} & \multirow{2}{*}{$\begin{array}{l}\text { Average value } \\
\quad\left(\mathrm{g} \cdot \mathrm{m}^{-2}\right)\end{array}$} \\
\hline & $\mathrm{I}$ & II & III & \\
\hline Syringa oblata & 4.986 & 5.258 & 5.495 & $5.645 \mathrm{Aa}$ \\
\hline Ligustrum & 2.289 & 2.695 & 2.409 & $2.620 \mathrm{Bb}$ \\
\hline Forsythia & 1.118 & 0.889 & 0.945 & $1.057 \mathrm{Cc}$ \\
\hline P.thomsoni & 0.871 & 0.922 & 0.783 & $0.915 \mathrm{CDcd}$ \\
\hline Lonicera maackii & 0.984 & 0.741 & 0.850 & $0.886 \mathrm{CDcd}$ \\
\hline Weigela florida & 0.710 & 0.891 & 0.790 & 0.799CDcde \\
\hline Amygdalus triloba & 0.596 & 0.708 & 0.680 & 0.688CDEde \\
\hline Cornus alba & 0.589 & 0.611 & 0.628 & 0.624DEe \\
\hline Lonicera Japonica & 0.471 & 0.319 & 0.338 & $0.394 \mathrm{Ef}$ \\
\hline
\end{tabular}


Table 4. Rank of dust-stagnation capacity of deciduous trees

\begin{tabular}{lcccc}
\hline Species of plants & \multicolumn{3}{c}{ Dust-stagnation volume $\left(\mathrm{g} \cdot \mathrm{m}^{-2}\right)$} & $\begin{array}{c}\text { Average value } \\
\left(\mathrm{g} \cdot \mathrm{m}^{-2}\right)\end{array}$ \\
\cline { 2 - 4 } & $\mathrm{I}$ & II & III & \\
\hline Populus tomentosa & 3.710 & 4.074 & 3.822 & $4.192 \mathrm{Aa}$ \\
Acer truncatum & 2.943 & 3.817 & 3.391 & $3.543 \mathrm{Bb}$ \\
Syringa amurensis & 1.508 & 1.831 & 1.654 & $1.777 \mathrm{Cc}$ \\
Ailanthus altissima & 1.037 & 1.123 & 1.224 & $1.215 \mathrm{Dd}$ \\
Sophora japonica & 0.967 & 1.114 & 1.079 & $1.080 \mathrm{Dd}$ \\
Ulmus macrocarpa & 0.531 & 0.714 & 0.655 & $0.648 \mathrm{Ee}$ \\
Salix babylonica & 0.511 & 0.612 & 0.554 & $0.568 \mathrm{Ee}$ \\
Prunus persica & 0.582 & 0.529 & 0.526 & $0.549 \mathrm{Ee}$ \\
Poplus albaxberolinensis & 0.456 & 0.388 & 0.414 & $0.446 \mathrm{Ee}$ \\
Ginkgo biloba & 0.403 & 0.396 & 0.367 & $0.407 \mathrm{Ee}$ \\
Robinia pseudoacacia & 0.361 & 0.297 & 0.345 & $0.374 \mathrm{Ee}$ \\
\hline
\end{tabular}

From the research, it was gotten than the vertical height of plants with different types was different and so was the dust volume accepted, thus influencing the effect of dust stagnation (Table 3 and Table 4). The dust-stagnation capacity from big to small was: shrubs $(1.682 \mathrm{~g} \cdot \mathrm{m}-2)>$ deciduous trees $(1.345 \mathrm{~g} \cdot \mathrm{m}-2)>$ vines $(0.655 \mathrm{~g} \cdot \mathrm{m}-2)$. The analysis of the dust-stagnation volume among shrubs, vines and deciduous tree showed the difference between shrubs and trees was obvious at the level of 0.05 and extremely obvious at the level of 0.01 . With the characters of tall and big body, trees mainly stagnated and filtered the fallen and floating dust outside; due to lower than trees in height, shrubs could effectively reduce the blowing dust on ground; though the dust-stagnation capacity was low, vines could stagnate dust at different height. Hence, for those campus green space with secondary blowing dust, besides planting wide-leaf-trees of which the dust-stagnation was strong and paid attention on overshadow, if dust-stagnation effect was needed to improve, we should also added shrubs and vines of which dust-stagnation capacity was strong to enrich the greening levels of plants and improve dust-stagnation effect on the whole ${ }^{[6]}$.

\section{Optimization Suggestions of Plant Landscape of Campuses}

3.1 Optimization Suggestions of Living Space. The living space mainly includes dorm quarters and surrounding areas. The plants in such areas should be able to create a leisured and comfortable living environment and achieve the effect to improve the quality of life, so we should select the trees, shrubs and grasses of which the overshadow effect is nice, ornamental capacity is strong and without peculiar smell to plant harmoniously. Trees could be selected as follows: Populus alba L. with double-color leaves, figure-elegant Salix babylonica, Ginkgo biloba of which the leaves will become yellow in autumn, Prunus persica $f$ which will bloom white flowers in spring, and evergreen Pinus tabuliformis Carrière, Sabina chinensis, etc; shrubs could be selected as follows: Syringa oblate of which the fragrance is nice, Forsythia suspensa Vahl, Cerasus tomentosa (Thunb.) Wall, Amygdalus triloba, Prunus armeniaca and other flower-appreciation and fruit-appreciation plants. Specially notice the collocation proportion of plants with colorful leaves, flower-blooming plants and fruit-appreciation plants, through the variation of the color of flowers, leaves and fruits, give different scenery to different seasons, endow rhythm of plant landscape in time and space and form a effect that every season has scenery to appreciate.

3.2 Optimization Suggestions of Traffic. The primary roads inside campuses are one of the main pollutant sources of PM2.5. The plants with high dust-stagnation capacity, strong overshadow capacity and good appreciation effect should be selected to plant at sides of the roads. The 
overshadow trees with strong dust-stagnation capacity and large green quantity should be selected such as Populus bolleana, acer truncatum and Sophora japonica Linn.; for secondary roads, garden greening species with dust-stagnation capacity merely inferior to trees in primary roads could be selected such as Syringa amurensis, Ulmus macrocarpa and Salix babylonica. Shrubs can effectively control the blowing dust of ground, so besides trees, shrubs must be planted with collocation and then the best dust-stagnation capacity can be only achieved. According to dust-stagnation capacity, Syringa oblate, Ligustrum obtusifolium, Forsythia suspensa Vahl could be selected as shrubs band at road sides to plant along with trees, thus not only satisfying the premise of optimization of dust-stagnation, but also achieving a better appreciation effect.

3.3 Optimization Suggestions of Teaching Quarters. The main purpose of the environment of teaching quarters should be improving study quality, so plants with strong, dust-stagnation capacity, good the overshadow effect, no peculiar fragrance, no harm to pedestrians, not easy to attract mosquitoes should be selected to plant. Trees with good overshadow effect and not easy to attract mosquitoes such as syringa reticulata var. mandshurica, acer truncatum could be selected as the main shadow array attached with shrubs with strong dust-stagnation such as Syringa oblate, Amygdalus triloba, Lonicera maackii.. P.thomsoni could be planted on walls to stagnate particles from different heights, enhance vertical greening of teaching quarters and achieve functions of preventing from sunshine and sunstroke.

3.4 Conclusion. At present, the issues existed in the plant landscape status of universities campuses are that the types of plant landscape are single, the proportions of evergreen plants are small, the appreciation character of plants is not satisfactory, the dust-stagnation capacity of plants is low, etc. Therefore, in the design of plant landscape of universities in future, the configuration modes of plant communities should be enhanced to avoid simple repeating which will make people feel boring; the intensity of dust-stagnation capacity should be taken as main conditions to filter plant species; increase evergreen plants properly and select the plant species with high aesthetic evaluation, fully combined with the climate features in north-eastern regions form plant landscape that can be appreciated all the year which the winner is as long as 6 months.

\section{Acknowledgements}

This work was financially supported by the The National Natural Science Fund "Research on Plant Selection, Spatial Configuration and Layout Optimization of Cold Regions Based on the Reduction of Atmospheric Inhalable Particulate Matter" (No: 31470031), science and technology projects of Ministry of housing and urban rural construction "Research on Strategies of the Planning of Green Space of Urban Streets of Shenyang Which Can Reduce the Atmospheric Inhalable Particulate Matter" (No.: 2016-R2-022)

\section{References}

[1] Cuizhen Wei.Zhenbao Zhang.Lingyun Zhou.Research on the Diversity of Species among Different Herb Communities in Wetlands at Downstream Side of Yellow River[J]. Wetland Science. 2012(3): 58-63.

[2] Xuan Qin.Jiaye Lai.Chun Mao.Suping Xie.Investigation and Analysis of the Diversity of Plants of Green Space at River Streamside of Gardens in Nanning[J]. Journal of Guangxi Science Academy. 2010(5):119-123.

[3] Ruyuan Yu.Zhaofei Fan.Linke Fan.Qifan Tian.HaiPing Yan.Analysis of Quality and Landscape Interests of Man-made forests in National Forest Park in Xishan, Beijing[J]. Journal of Beijing Forestry University. 1995(1):60-67.

[4] Haiyan Huang.Hongwei Yan. Functional Analysis of Plant Landscape in Campus of Shenyang Agriculture University. Agricultural Science of Heilongjiang. 2011（7） : 89-90. 
[5] Lin Zhao.Hongyu Mao. Investigation and Evaluation of plant Landscape of Shenyang Universities Based on AHP[J]. Northern Horticulture. 2013 (07) :85-89.

[6] Mengmeng Liu.Lixin Yang.Jian Zhang.Yongfeng Yang. Investigation and Analysis of Dust-stagnation Effect of Main Greening Plants in Campuses of Universities. Journal of Shenyang Agriculture University (Edition of Society and Science0, 2012-01, 14 (1):115-118. 